DOI: 10.20472/IAC.2018.042.008

\title{
YURY DUBININ
}

Boreskov institute of catalysis SB RAS, Russian Federation

EKATERINA DUBININA

Boreskov institute of catalysis SB RAS, Russian Federation

\section{COMMERCIALIZATION OF THE SCIENTIFIC DEVELOPMENTS ON THE EXAMPLE OF THE PROJECTS IMPLEMENTATION IN SMALL ENERGY}

\begin{abstract}
:
A common interdisciplinary problem, characteristic for many developed and developing countries, is the problem of the demand for fundamental and applied scientific developments. In addition, on the way to introduction into the industry and the real sector of the economy, scientific developments face many obstacles, which are extremely difficult to overcome without support from the state or private business. In this paper, the experience of successful developments implementation in the field of small-scale power engineering from the point of view of interaction between sciences, the state and business is considered. As an example, the corresponding developments of the Boreskov Institute of Catalysis of the SB RAS (Novosibirsk, Russian Federation) were considered.
\end{abstract}

\section{Keywords:}

Commercialization, scientific developments, small energy, fluidized bed technology 
At present, the fundamental achievements and applied developments of Russian science are in poor demand by Russian economy and business. This, in turn, increases the reality of the threats not only of technological backwardness but also of the country's security. This problem is not exclusively Russian. Developed and developing countries also include its solution among strategic priorities. The deficit of "diffusion of innovations" is seen as an important problem for the countries of the European Union.

The problem of strengthening the practical relevance of scientific developments is connected with the fact that it depends not only on the amount of scientific developments financing (public and private) but also on the institutional environment and forms of interaction between science and wide range of potentially interested parties. The new forms of breakthrough scientific research organization correspond to its interdisciplinary nature. Changes in the organization of scientific research and the promotion of their results include: the convergence of the scientific research and experiments processes; search for new forms and mechanisms for organizing scientific and innovative activities; transformation of science and innovation financing models; strengthening the role of the government in stimulating demand for innovation and protecting the interests of national stakeholders.

Practice shows that despite all the unconditional importance of scientific and technological results of research and development the center of gravity in their management in modern conditions shifts to economic justification search for potential customers, areas of application and access to attractive markets. At the same time the search for new models of interaction between fundamental and applied science, government, business and education in the process of scientific and innovative activity organizing should be based on methodological developments and the best world and domestic practices, taking into account modern development trends.

This work shows the experience of scientific developments commercialization on the example of Boreskov institute of catalysis SB RAS (Novosibirsk, Russian Federation) developments in the field of small-scale power engineering. This experience is considered from the point of view of interaction between science, the state and business. Among the considered developments, the most promising technology was chosen from the point of view of introduction into the real sector of the economy. The route along which the technology passed from laboratory to commercial use was considered. Based on the successful experience of innovative fuel combustion technology implementation, a number of universal steps have been compiled. These steps can be used to improve the interaction between fundamental and applied science, government, business and 
education, which will lead to efficiently implementation and commercialization of different scientific developments.

\section{Scientific developments of the Boreskov Institute of Catalysis in small energy}

First of all, to fulfill the goals set in the work, all the developments of the Institute of Catalysis in the field of small-scale power engineering were considered and studied. Since the total number of developments is quite large, the main ones with significant commercialization potential are selected and presented in this paper. All considered developments in one form or another have the experience of industrial implementation.

\subsection{Catalytic air heater}

Catalytic air heaters are based on two-stage combustion of liquid (diesel fuel) or gaseous fuel (natural gas). Fuel, with the help of injectors, is fed into the chamber, where its combustion takes place. The resulting flue gases are diluted with air by means of a centrifugal fan to reach the desired temperature. Obtained mixture is fed to a second chamber where a catalytic filter with a block catalyst of honeycomb structure is installed. On the catalytic filter at a temperature of $400-800{ }^{\circ} \mathrm{C}$ occurs a deep oxidation of the fuel incomplete combustion products and carbon monoxide as well as the reduction of nitrogen oxides. The heater scheme is shown in Figure 1.

Figure 1. Catalytic air heater

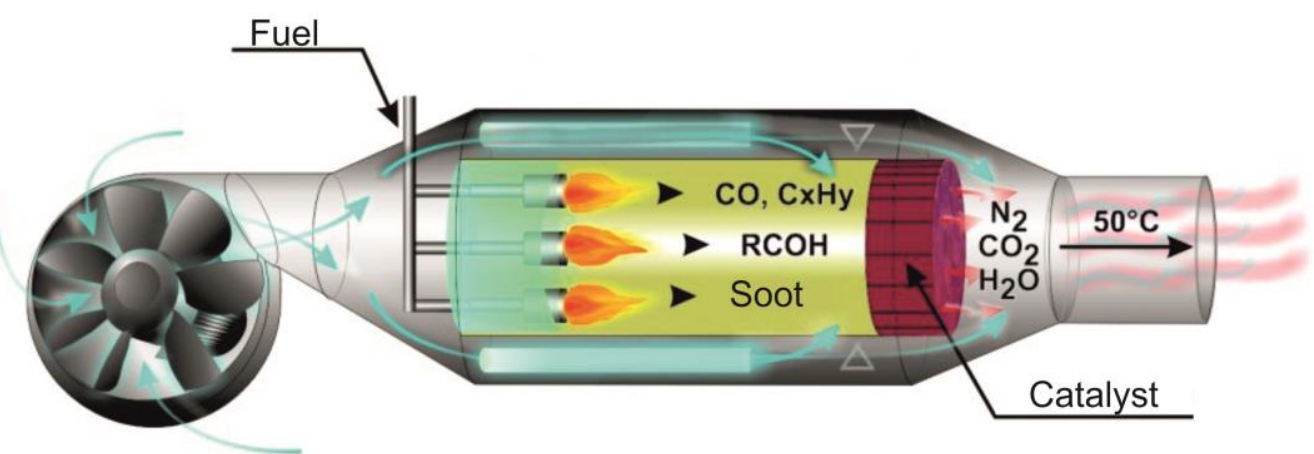

Source: Archives of the Boreskov Institute of Catalysis SB RAS

Advantages of this technology are its simplicity, high environmental safety of fuel combustion, reduced metal capacity of construction and reliability in operation.

To date, a standard series of such air-heating units with a thermal power from 0.03 to 3 MW have been developed. The developed devices can be used for heating of 
greenhouses, storages, hangars, industrial and auxiliary rooms for non-household purposes.

\subsection{Catalytic gas fireplaces for residential use}

Based on the same principle (section 2.1), fireplaces for local heat supply have been developed at the Institute of Catalysis of the SB RAS. Devices are designed both for heating of permanent structures - cottages, garages, warehouses, workshops, apartment houses, and in the field for the heating of tents, cabins, car kungas, etc. The principle of the heater is based on the flameless combustion of gaseous fuel on the surface of the catalyst in heating elements developed at the Institute of Catalysis of the SB RAS. The heating device is economical and reliable. It operates at temperatures from minus $35^{\circ} \mathrm{C}$ to $+25{ }^{\circ} \mathrm{C}$ and relative humidity up to $98 \pm 2 \%$. Small dimensions and weight, autonomy of use allow the heater to be used even in emergency situations.

The appearance of these devices is shown in Figure 2.

Figure 2. Catalytic gas fireplace

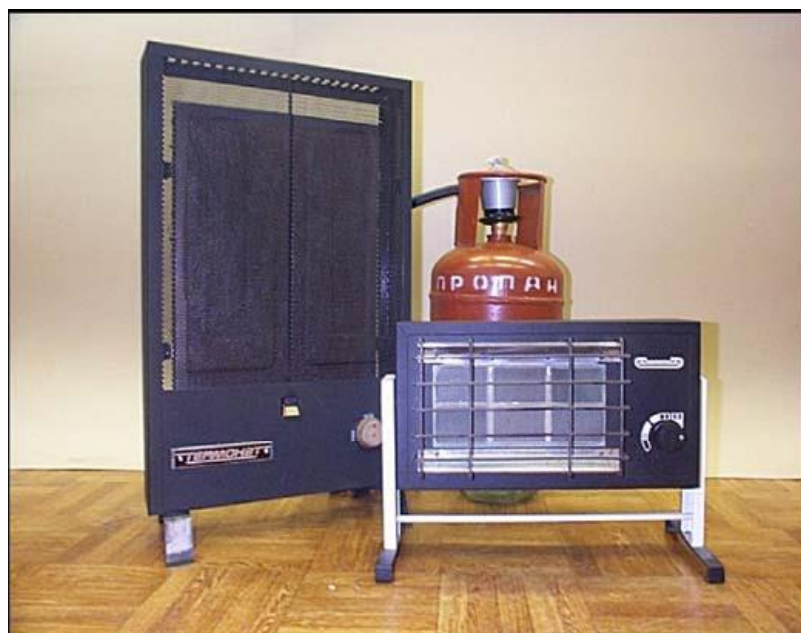

Source: Archives of the Boreskov Institute of Catalysis SB RAS

\subsection{Autonomous gas-turbine plants (GTP) with a catalytic combustion chamber}

Widely known in the energy and power generation market are so-called gas turbines of low power (tens of $\mathrm{kW}-2 \mathrm{MW}$ ). These plants have a number of advantages over the traditionally used diesel generators. First of all, they have significantly higher environmental safety, simplicity of operation and maintenance. One of the most important parts of such systems is the fuel combustion chamber. A fundamentally new method was proposed at the Institute of Catalysis of the SB RAS - catalytic combustion of fuel. This method allows one to achieve even higher environmental performance and fuel 
combustion efficiency. The scheme of the catalytic combustion chamber of the fuel in the gas turbine plant is shown in Fig. 3.

Figure 3. Catalytic combustion chamber for GTP

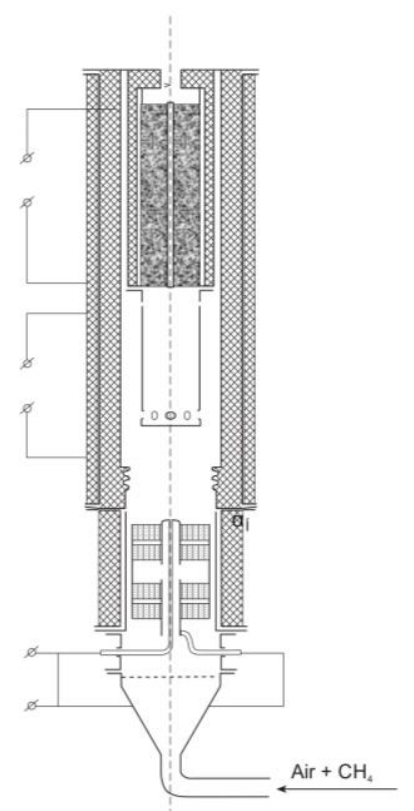

Source: Archives of the Boreskov Institute of Catalysis SB RAS

2.4. Catalytic heat-supplying units (CHSU)

Catalytic heat-supplying units are based on fuel combustion in the fluidized bed of a deep oxidation catalyst. The scheme of the combustion plant is shown in Figure 4. 
Figure 4. Catalytic heat-supplying unit

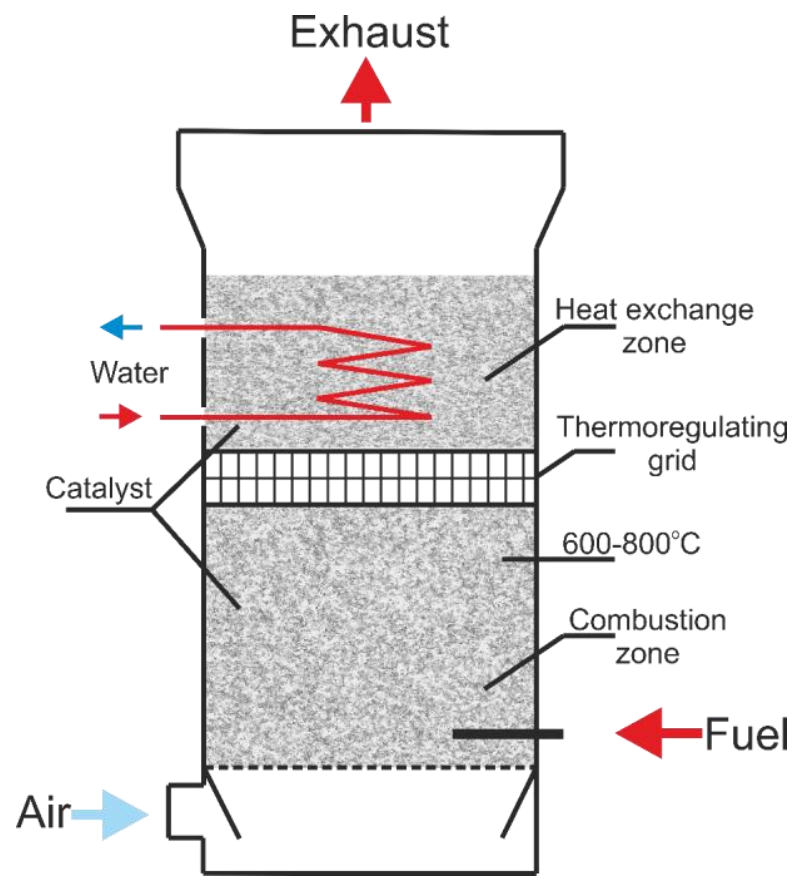

Source: Archives of the Boreskov Institute of Catalysis SB RAS

Compared with conventional combustion methods, the fluidized bed combustion technology has a number of significant advantages. The most significant of them are:

- Low temperature range of combustion $\left(650-750^{\circ} \mathrm{C}\right)$;

- Reduced size and metal capacity of constructions;

- Absence or low concentration of pollutants $\left(\mathrm{CO}, \mathrm{NO}_{x}, \mathrm{SO}_{x}\right.$, dioxins, soot) in flue gases.

The key advantage of this technology is its universality - in addition to traditional fuels (coal, gas, diesel fuel), combustion in the fluidized bed of catalyst can be used for efficient processing of substandard fuels (such as oil shale, tar sands) and waste (including municipal services sewage sludge). Thanks to the advantages listed above, the technology becomes extremely attractive for commercialization and implementation.

Catalytic heat-supplying units based on the combustion of fuels in the fluidized bed of the catalyst were taken as an example for further consideration. These installations have passed a successful path from laboratory technology to industrial facilities. In the late 2000s - early 2010s, several boiler houses were built on the basis of the CHSU. These boiler houses are still functioning and demonstrate economic and ecological efficiency. 


\section{Commercialization of $\mathrm{CHSU}$}

The CHSU commercialization experience based on the technology of combustion in the fluidized bed of catalyst consists of two key steps. In both cases, the introduction of technology was carried out within the framework of target programs in the field of energy efficiency and energy supply - regional and federal. Thanks to these programs, five coalfired boiler houses have been installed, providing heat to railway stations and adjacent facilities in different regions of the Russian Federation.

Nevertheless, a key factor in the success of the introduction of the technology under consideration was cooperation with a private engineering company (SPKB Energy), which in both cases acted as an industrial partner of the Boreskov Institute of Catalysis. Despite the complexity of the technology expertise (there are no direct analogs for this technology in Russian Federation and abroad), SPKB Energy has collaborated with the Institute and participated in the implementation of projects as a design and construction organization.

\subsection{Regional Program for the energy supply of the Kemerovo region}

Participation in the regional target program on energy supply in the Kemerovo region in 2007 can be considered as the first stage of the CHSU commercialization. As a part of this program, it was necessary to modernize the existing boiler house at the Artyshta-2 railway station. Together with the company SPKB Energy, a project of the CHSU was developed based on the technology of coal combustion in the fluidized bed of catalyst. Part of this project was financed from public funds, part was sponsored by the territorial branch of the Russian Railways (Russian Railways owns railway stations and infrastructure facilities). In 2008, a new boiler house CHSU-3.0 (3.0 - means the boiler house power of $3 \mathrm{Gcal} / \mathrm{h}$ ) was built and put into operation. Indicators of the new $\mathrm{CHSU}$ efficiency in comparison with the old boiler house are given in Tables 1 and 2. The appearance of the old boiler house and the new CHSU are shown in Figure 5. 
Table 1. Efficiency of CHSU-3.0 (Artyshta-2) in comparison with an old boiler house

\begin{tabular}{|lcc|}
\hline \multicolumn{1}{|c}{ Parameter } & CHSU-3.0 & Old boiler house \\
\hline $\begin{array}{l}\text { Coal consumption, } \\
\text { tons/month }\end{array}$ & 432 & 906 \\
\hline $\begin{array}{l}\text { Cost of 1 Gcal production, } \\
\text { Rub. }\end{array}$ & 331,5 & 1050 \\
\hline $\begin{array}{l}\text { The cost of fuel and energy } \\
\text { resources, ths. Rub./month }\end{array}$ & $\begin{array}{c}522 \text { (с учетом } \\
\text { каталиатора) }\end{array}$ & 969 \\
\hline $\begin{array}{l}\text { Fuel consumption efficiency, } \\
\%\end{array}$ & 93 & $\sim 45-60$ \\
\hline
\end{tabular}

Source: Scientific and Technical Reports of the Boreskov institute of catalysis SB RAS

Table 2. Ecological efficiency of CHSU-3.0 in comparison with an old boiler house

\begin{tabular}{|ccc|}
\hline & \multicolumn{2}{c|}{ Concentration, $\mathbf{g} / \mathbf{s}$} \\
Toxic compounds & CHSU-3.0 & Old boiler house \\
\cline { 2 - 3 } & 0,85 & 12,0 \\
\hline Mechanical impurities & 0,44 & 3,2 \\
\hline $\mathrm{NO}_{\mathrm{x}}$ & 1,1 & 3,6 \\
\hline $\mathrm{SO}_{2}$ & 2,4 & 36,0 \\
\hline $\mathrm{CO}$ & & 3 \\
\hline
\end{tabular}

Source: Scientific and Technical reports of the Boreskov institute of catalysis SB RAS

As it can be seen from the data in Tables 1 and 2, CHSU-3.0 demonstrates much higher efficiency, environmental friendliness and economy in comparison with the old boiler house. The benefit is mostly due to the use of a new catalytic combustion technology. The introduction of this development allowed to save up to several million rubles per year. 
Figure 5. Old boiler-house (left picture) and CHSU-3.0 (right picture)
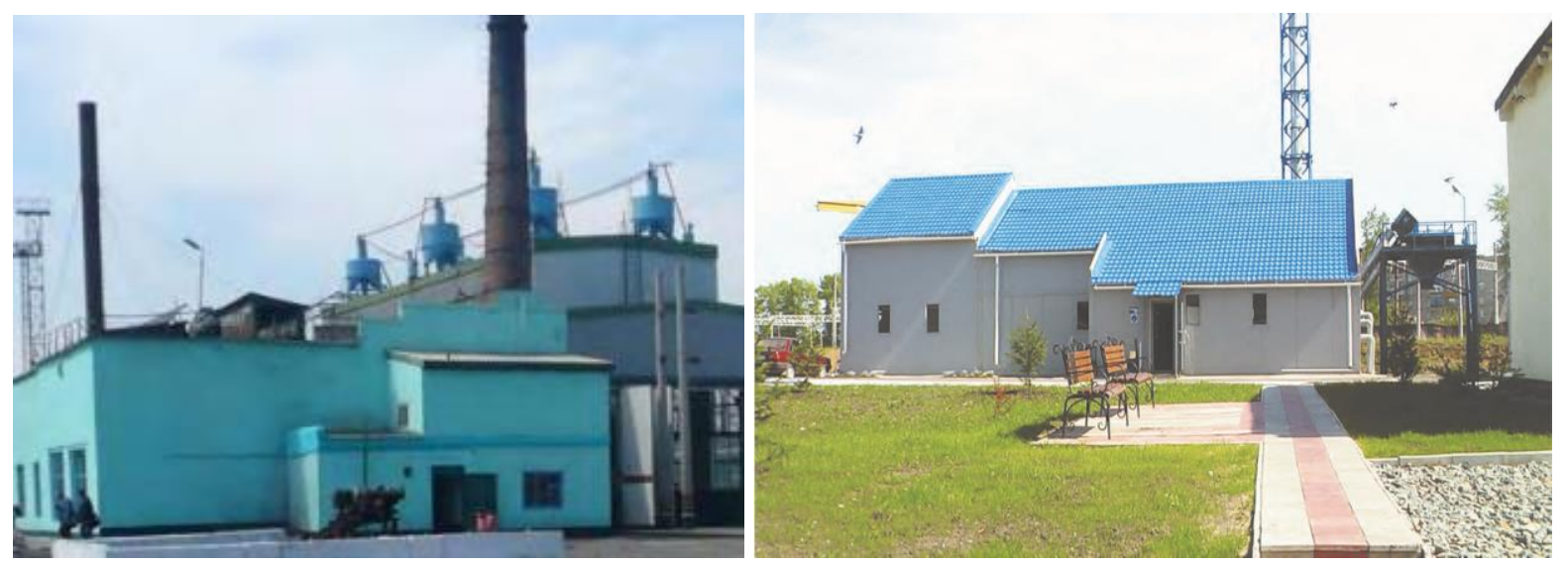

Source: Scientific and Technical reports of the Boreskov institute of catalysis SB RAS

\subsection{Federal program on energy supply}

The second stage in the implementation of CHSU technology was participation in the Federal Targeted Program "Implementation of integrated projects, including the development of competitive technologies intended for subsequent commercialization in the field of energy efficiency, energy supply and nuclear power." Based on the experience gained during the introduction of combustion in the fluidized bed technology in the creation of CHSU-3.0 at the Artyshta-2 station, the Boreskov Institute of catalysis, together with SPKB Energy as an industrial partner, received a support for the creation of four new CHSU at railway stations in various regions of the Russian Federation. The second industrial partner was Russian Railways. As in paragraph 3.1., the project was funded $50 / 50$ - half was allocated from public funds, half was off-budgetary funding by industrial partners. The distribution of project funding by years is shown in Table 3.

Table 3. Financing of the CHSU implementation project, million rubles

\begin{tabular}{|l|c|c|c|c|}
\hline Source & $\mathbf{2 0 1 1}$ & $\mathbf{2 0 1 2}$ & $\mathbf{2 0 1 3}$ & Total \\
\hline Budget funds & 55,65 & 55,7 & 55,65 & 167 \\
\hline off-budget funds & 56,330041 & 57,095942 & 56,470026 & 169,896009 \\
\hline Total & 111,980041 & 112,795942 & 112,120026 & 336,896009 \\
\hline
\end{tabular}

Source: Scientific and Technical reports of the Boreskov institute of catalysis SB RAS 
Due to this federal target program, the following CHSUs were built and put into operation in the period from 2011 to 2013 :

1) Boiler house CHSU-1.0 (power of $1.0 \mathrm{Gcal} / \mathrm{h}$ ) at the railway station Yurga (Kemerovo region);

2) Boiler house CHSU-3.0 (power of $3.0 \mathrm{Gcal} / \mathrm{h}$ ) at the railway station Kulunda (Altai region);

3) Boiler house CHSU-2.0 (power of $2.0 \mathrm{Gcal} / \mathrm{h}$ ) at the railway station Abakumovka (Krasnoyarsk region);

4) Boiler house $\mathrm{CHSU}-6.0$ (power of $6.0 \mathrm{Gcal} / \mathrm{h}$ ) at the railway station Magdagachi (Amur region);

The appearance of the constructed CHSU is shown in Figure 6.

Figure 6. Different CHSU. A - CHSU-1.0 (Yurga), B - CHSU-3.0 (Kulunda), C - CHSU-2.0 (Abakumovka), D - CHSU-6.0 (Magdagachi).

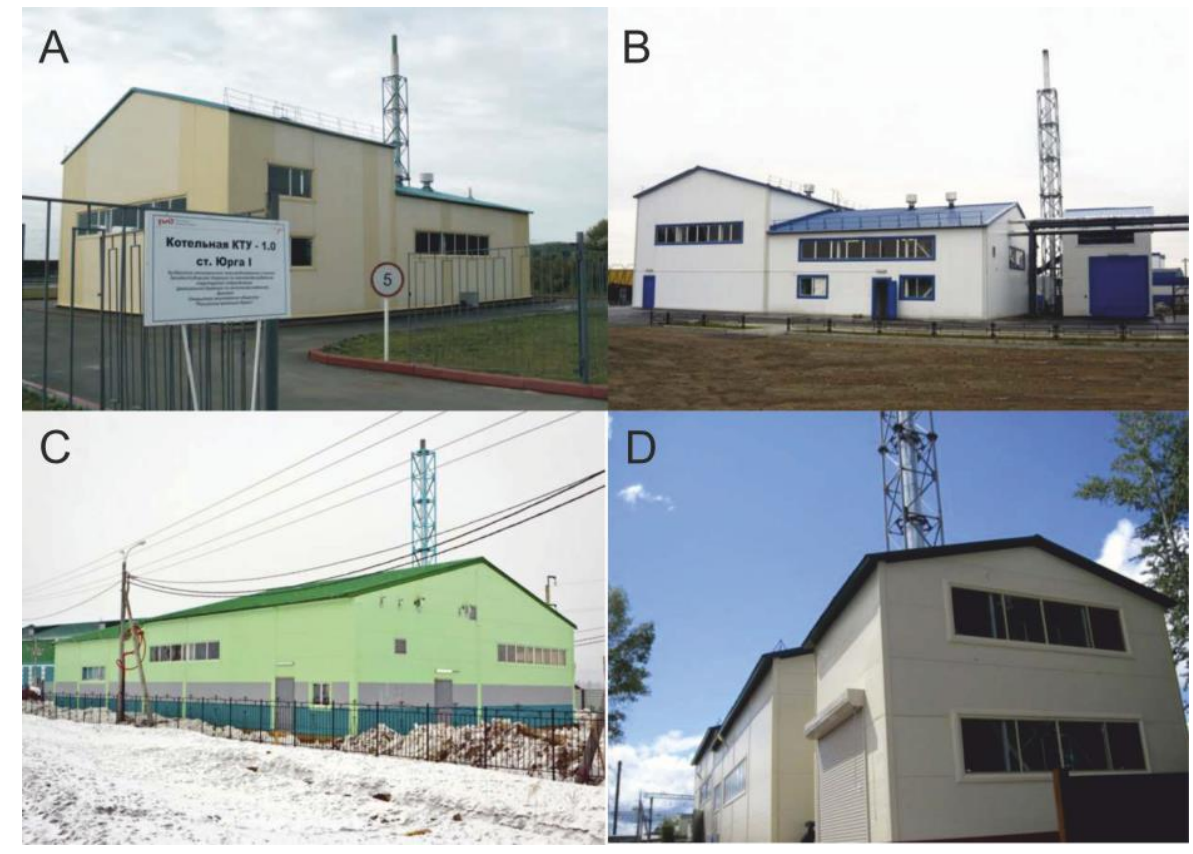

Source: Scientific and Technical reports of the Boreskov institute of catalysis SB RAS

All implemented facilities are distinguished by high performance in economic efficiency and environmental safety. Thus, due to the competent interaction between science (Boreskov Institute of Catalysis SB RAS), the state (regional and federal target programs) and business (Russian Railways, SPKB Energy), it was possible to implement high 
technology in the real economic sector. Created in the framework of these projects catalytic heat supply units function to the present and allow saving tens of millions of rubles, compared to traditional boiler plants that were previously used. At the same time, the environmental safety of $\mathrm{CHSU}$ are several times higher than those for traditional boiler houses.

\section{Proposed activities for the scientific developments implementation}

Proceeding from the example considered in paragraph 3, three key components necessary for the successful implementation of scientific development (including in the field of small-scale energy) can be singled out: actual scientific development, active state assistance and a reliable business partner. In this case, bilateral relations between each component of this "implementation triangle" are necessary (Figure 7).

\section{Figure 7. Trilateral interaction of science, state and business}

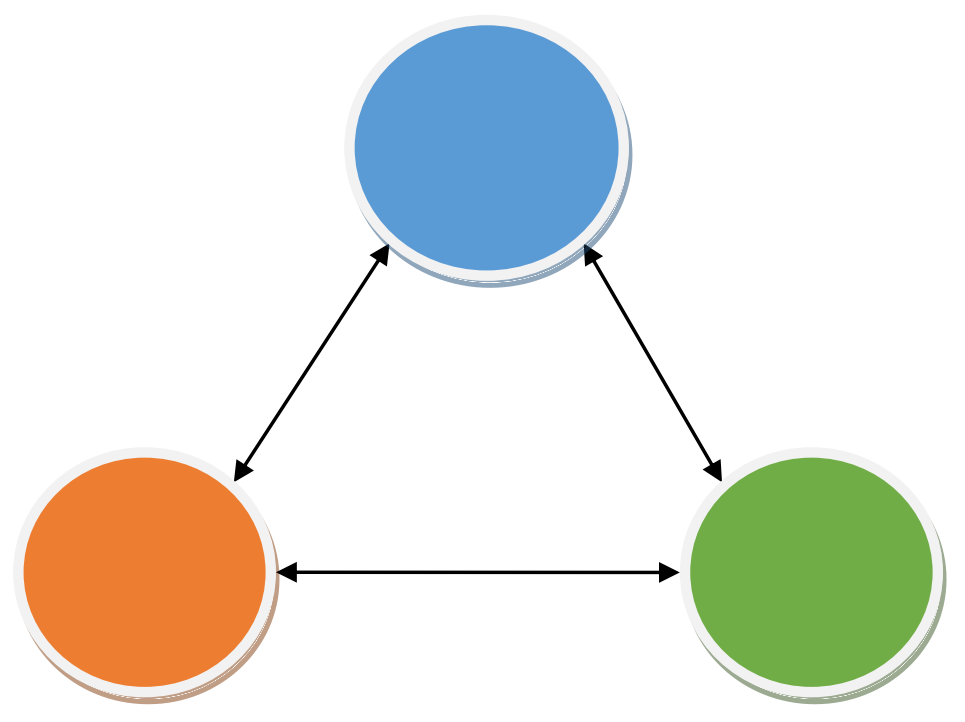

Source: own assumption of interaction

However, examples of a truly successful introduction of scientific developments in the real economy are more sporadic. To shift the situation towards the increasing of the developments commercialization degree, a set of measures and proposals should be developed. Based on the successful experience of CHSU implementation and the assumption of the effectiveness of the tripartite interaction "science-state-business", we propose the following measures aimed on solving the indicated problem: 
1) Advertising of scientific developments

It is well known that advertising is the main engine of trade. As well as to conventional consumer goods, advertising laws can be applied to scientific developments. Moreover, there are a huge number of ways to convey information to the target audience, which must be used. Today, the main way of communication between science and the potential consumer of scientific developments are exhibitions. However, due to their specifics, not all such events lead to successful interaction and commercialization. For more successful coverage of scientific achievements, it is necessary to use all available media, including coverage in social networks. The constant "pumping" of the information field should lead to an increase in the interest of the audience, including potential consumers of technologies.

\section{2) Active interaction between the state and science}

The experience of CHSU implementation shows that the implementation of target programs of various levels (from municipal to federal) is an effective way to commercialize scientific developments in various fields. However, due to various factors, not all the developments pass through the competitive selection. In addition, some technologies are not even applied to such programs. In our opinion, to strengthen the interaction between science and the state, it is necessary to create a constantly updated integrated database of scientific developments. The introduction of such approach will make it possible to learn more about the existing achievements of fundamental and applied science and will help to find solutions to emerging problems and requests more quickly. Moreover, such a database can be transformed into an online interactive development map. Such an approach will make it easier and quicker to find contact with technologies developers.

\section{3) Interaction between the state and business}

In addition to strengthening the relations with science, the state can develop the cooperation with business. In this case, one of the possible actions may be drawing up a database of requests from business - those problems and issues that they would like to solve, including using domestic scientific developments. Thus, if there are inquiries from business and existing scientific and technological decisions from science, the state can act as an active intermediary, contributing to the creation of new contacts and interactions. In addition, having the information on existing inquiries from business, science can develop new relevant studies with visible prospects for implementation. 
4)

"Seeding" of the scientific developments

Often, only the projects with the obviously high potential of commercialization are accepted for the implementation. Unfortunately, not all scientific laboratories (or even institutes) can afford to bring their development to this state in a short period of time. To solve this problem, similarly with the development of start-up projects around the world, within the framework of the trilateral interaction discussed above, the state can carry out, so-called, "seeding" of the scientific developments. In this case, it is necessary to invest relatively small funds for prototyping and further development, in accordance with the proposed scientific projects. As a result, out of hundreds of "seeded" developments, dozens (or even singles) of projects will come to the stage of subsequent development, but their potential will be high enough to cover the invested expenses and bring profit. In addition, the development funding at an early stage will stimulate researchers to create and develop new technologies and solutions.

The above list of activities is certainly not complete and comprehensive. However, the introduction of the described points will allow the process of scientific developments commercialization (including in the field of small energy) to be brought to a new level and will have a positive effect on the economic sector.

\section{Conclusions}

In this paper, the developments of the Boreskov Institute of Catalysis SB RAS in the field of small-scale power engineering were considered. The technology of combustion in the fluidized bed of catalyst was chosen from the presented developments for the further consideration. On the basis of this technology five CHSUs of various heat power were created and commissioned in several regions of the Russian Federation. The success of this technology implementation was due to the competent tripartite interaction of science, government and business. Based on the CHSU implementation experience, a number of measures were proposed. These measures could promote the commercialization and introduction of scientific developments in the real sector of the economy. These activities include the promotion and advertising of scientific developments; strengthening of interaction between the state and science, the state and business, science and business; creation of the practice of the scientific developments "seeding".

\section{$6 \quad$ References}

ISMAGILOV Z.R., KERZHENTSEV M.A., YASHNIK S.A., SHIKINA N.V. Catalysts for efficient fuel combustion. Russian Nanotechnologies. 2009. V. 4, N. 11-12, pp. 32-34. 
SIMONOV A.D., FEDOROV I.A., DUBININ Y.V., YAZYKOV N.A., YAKOVLEV V.A., PARMON V.N. Catalytic Heat-Generating Units for Industrial Heating. Catalysis in Industry. 2013. V. 5. N 1. pp. 4249

ISMAGILOV Z.R., ZAINIEVA I.ZH., ARENDARSKY D.A., DREMIN N.V., MIKHAILOV V.V. Gas catalytic fireplace. Patent RF, N 2057277, 1996.

V.N. PARMON, Z.R. ISMAGILOV, O.N. FAVORSKY, A.A. BELOKON, V.M. ZAKHAROV. Application of catalytic combustion chambers in gas-turbine installations for decentralized power supply. Bulletin of the Russian Academy of Sciences. 2007. V. 77, N. 9, pp. 819-826.

KULESHOV V.V, SELIVERSTOV V.E. Science, power, business-triangle of re-industrialization. In the world of science. 2016. N. 6. Special Issue. pp. 9-15.

ASEEV A.L. Russian science: the time of tests. In the world of science. 2015. N. 12. pp. 114-121.

LENCHUK E.B., VLASKIN G.A. The Cluster Approach in the Innovation Development Strategy of Foreign Countries. Studies on Russian Economic Development. 2010. V. 21. N. 5. pp. 484-492 DOI: 10.1134/S1075700710050047 